\title{
MONITORING AND ANALYZING THE SURFACE SUBSIDENCE IN LANGFANG BY TIME-SERIES INTERFEROMETRIC RADAR TECHNIQUE
}

\author{
Lv Zhou ${ }^{1,2}$, Xuelin Wen ${ }^{1, *}$, Xianjian Lu ${ }^{1}$, Yujun $\mathrm{Shi}^{3}$, Jun Ma ${ }^{4}$, Di Zhang ${ }^{5}$ \\ ${ }^{1}$ College of Geomatics and Geoinformation, Guilin University of Technology, Guilin, China - (zhoulv_whu@163.com, \\ wxlwzj6389@hotmail.com,2008056@glut.edu.cn) \\ ${ }^{2}$ Key Laboratory of Geospace Environment and Geodesy, Ministry of Education, Wuhan University, Wuhan, China \\ ${ }^{3}$ Guangxi Deep Space Sail Engineering Survey and Design Co., LTD., Nanning, China - shiyujun1988@163.com \\ ${ }^{4}$ China Railway Siyuan Survey And Design Group Co., LTD, Wuhan, China - yangzhiqou.student@sina.com \\ ${ }^{5}$ School of Geodesy and Geomatics, Wuhan University, Wuhan, China - zhangdi@whu.edu.cn
}

KEY WORDS: PSInSAR, surface subsidence, Langfang area, spatial-temporal analysis

\begin{abstract}
:
In this paper, the subsidence change maps in Langfang were obtained using ASAR images covering Langfang area acquired from August 2007 to September 2010 with the Persistent Scatterer Interferometric Synthetic Aperture Radar (PSInSAR) technique. Surface subsidence spatial-temporal characteristics in Langfang was investigated. The analysis of experimental results show that 1) prominent uneven subsidence patterns were identified in Langfang. Specifically, surface subsidence rates ranged from $-77 \mathrm{~mm} / \mathrm{year}$ to $4 \mathrm{~mm} /$ year, and maximum subsidence rate was detected in Nanjianta Town; 2) the standard deviation of the target point subsidence rates in the study area ranges from $0.8 \mathrm{~mm} /$ year to $9.3 \mathrm{~mm} /$ year, $70.4 \%$ of the monitoring point standard deviations in study area are less than $3 \mathrm{~mm} /$ year; 3 ) surface subsidence time series presented nonlinear variation trend. The surface subsidence has a tendency to gradually expand around the center of Nanjianta Town, and the scope and trend of expansion to the north and west of Langfang are more serious.
\end{abstract}

\section{INTRODUCTION}

Langfang is located in the North China Plain, which is short of surface water resources. In order to satisfy the construction and development of the city, a large amount of groundwater needs to be extracted, so the surface deformation has occurred in the city. Traditional monitoring methods (e.g., levelling, Global Navigation Satellite System (GNSS)) can retrieve the subsidence information of a monitoring point with high temporal resolution and monitoring accuracy, although the high cost and low spatial resolution of these methods make it difficult to detect the urban subsidence funnel and make an overall analysis of urban surface subsidence.

In recent decades, the emergence of synthetic aperture radar (SAR) technique provides an effective method for effectively monitoring the urban overall surface subsidence. Differential Interferometric Synthetic Aperture Radar (DInSAR) overcomes the shortcomings of traditional monitoring methods such as low spatial resolution and high cost (Zhou et al, 2017), and has been successfully applied to seismic deformation detection ( $\mathrm{Li}$ et al, 2011), landslides (Calò et al, 2014), and urban surface subsidence analysis (Guo et al, 2016). However, DInSAR is susceptible to atmospheric delay, which is difficult to obtain high precision deformation information. In order to overcome the limitations of this technique, several time series InSAR techniques and methods have been proposed on the basis of the traditional DInSAR technique. Such as, the Persistent Scatterer Interferometric Synthetic Aperture Radar (PSInSAR), which can overcome decorrelation and atmospheric delay problems by identifying and analyzing point-like stable reflectors (Ferretti et al, 2001). Small Baseline Subset InSAR (SBASInSAR) is another time series InSAR method that obtain deformation information by analyzing distributed scatterers with high coherence based on an appropriate combination of interferograms (Beradino et al, 2002). Recently, many scholars have carried out research on surface subsidence based on the above-mentioned time series InSAR techniques, and have achieved some research results. Song et al. (2016) used improved SBASInSAR to study the time series land subsidence of Shengfang Town in Tianjin suburbs from 2007 to 2010 based on ALOS/PALSAR images. Zhou et al. (2016) adopted time series InSAR to monitor the surface subsidence in Beijing plain for a long time series, and analyzed the temporal-spatial evolution characteristics of the surface subsidence in this area. Bai et al. (2016) retrieved surface subsidence in Wuhan from October 2009 to August 2010 using TerraSAR-X images based on Multi-temporal InSAR, and the subsidence rates in the study area ranged from $-63.7 \mathrm{~mm} /$ year to $17.5 \mathrm{~mm} /$ year during the study period.

In this study, we first monitored the surface subsidence in Langfang area based on time-series InSAR technique. We then discussed and analyzed the accuracy of this monitoring technique. Finally, we comprehensively analyzed the temporalspatial characteristics of surface subsidence in Langfang area by combining the subsidence rate and the subsidence time series of some characteristic points in the study area during the study period.

\section{STUDY AREA AND DATA}

\subsection{Study Area}

Langfang is located in the east-central part of Hebei Province. Affected by geological structure, most area of Langfang is located in depressed areas. Langfang, located in the mid-latitude zone, is a warm temperate continental monsoon climate.

* Corresponding author 
Langfang is located in the core of Beijing-Tianjin-Hebei Urban Agglomeration and the hinterland of Bohai Sea Rim. Langfang has two districts, two county-level cities and six counties, with a total area of $6429 \mathrm{~km}^{2}$ and an urban area of $54 \mathrm{~km}^{2}$. The permanent resident population of Langfang was 4.795 million in 2018. Langfang is short of available surface water resources, and the industrial and domestic water is mainly provided by groundwater extraction. With the rapid development of social economy, groundwater exploitation Langfang is increasing, the surface subsidence area in Langfang is gradually expanding and developing. The study area in this study is within the black rectangular box in Figure 1 with a total area approximately 900 $\mathrm{km}^{2}$, covering most areas of Langfang City.

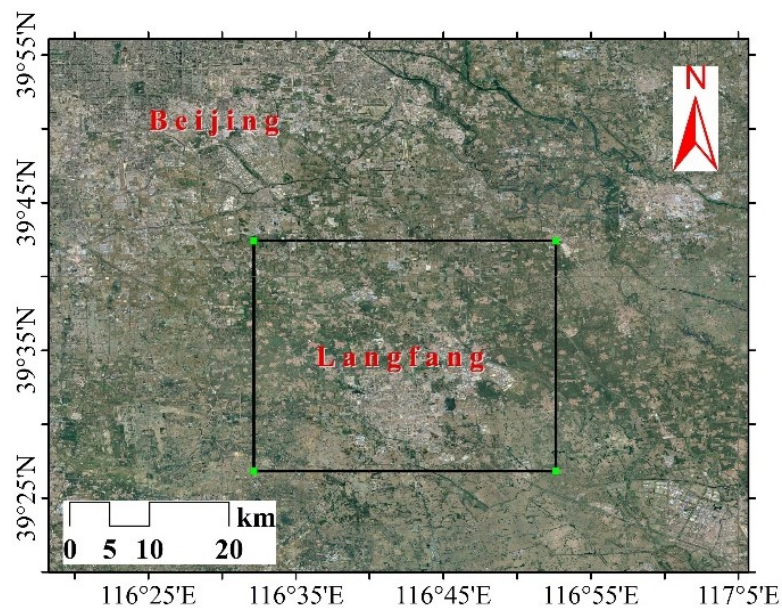

Figure 1. Location of study area. The black rectangle denotes the study area of this work.

\subsection{Data}

In this paper, we selected eighteen level 0 descending ENVISAT ASAR images acquired from 1 August 2007 to 29 September 2010, covering Langfang to estimate the line-ofsight (LOS) average surface subsidence rate and subsidence time series. ASAR image is in C-band $(5.6 \mathrm{~cm})$. The incident angle of the image center is approximately $20.8^{\circ}$.The selected ASAR images are in VV polarization mode with a resolution of $7.8 \mathrm{~m}$ in slant range and $4.6 \mathrm{~m}$ in azimuth. The three arc-second Shuttle Radar Topography Mission (SRTM) DEM data provided by the National Aeronautics and Space Administration (NASA) was adopted to remove the topographic phases. In addition, the orbit data precision of ASAR images were improved by using the DORIS orbit data released by the European Space Agency (ESA).

\section{TIME-SERIES INTERFEROMETRIC RADAR TECHNIQUE}

The time series InSAR technique adopted in this paper is PSInSAR technique. PSInSAR technique was proposed by Ferretti et al. (2001) in Italy. Firstly, based on the multi-scene SAR images (generally more than 25 scenes) covering the same area, this technique statistically analyzes the stability of amplitude and phase information in the images in time series. Then, according to the corresponding methods (such as the amplitude deviation index threshold method (Ferretti et al., 2000), the phase stability analysis method (Hooper et al., 2004), and the time-series coherence coefficient threshold method (Hooper et al., 2007), the point-like stable point targets (PSs) which are less affected by temporal and spatial baseline decorrelation are selected. The PSs have stable scattering characteristics and maintain high coherence at long time intervals (Perissin et al., 2006). Finally, the phase information of the selected PSs are analyzed, the corresponding noise phase is removed, and the deformation inversion model is established to calculate the deformation information. The basic data processing flow of PSInSAR technique is shown in Figure 2.

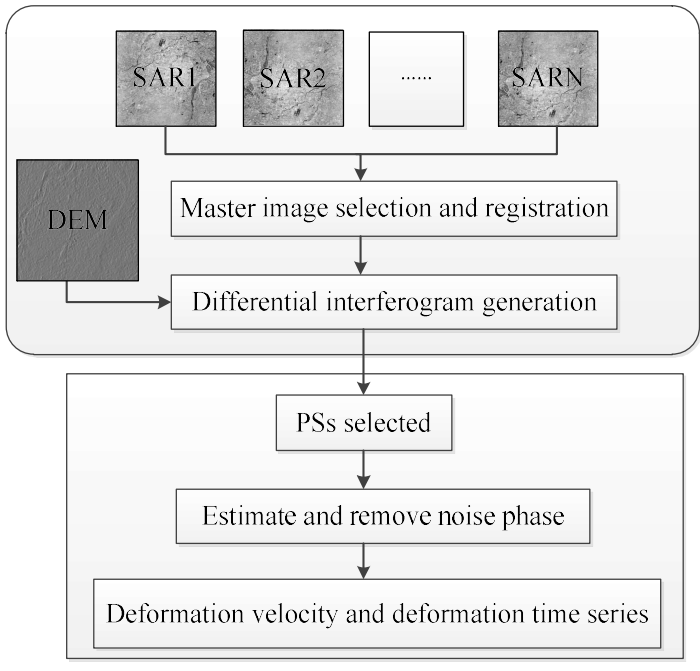

Figure 2. Flow diagram of the PSInSAR technique

Supposing $N$ SAR images are captured. Firstly, a SAR image was selected as the master image. Then, all the slave images were co-registered and resampled to the master image, and $\mathrm{N}-\mathrm{I}$ interferograms can be obtained by differential interferometric processing using external DEM and other data. In this study, the SAR image acquired on 14 October 2009 was selected as the master image and 17 pairs of interferograms were generated (Figure 3). According to the actual situation of the study area and SAR images, the corresponding PS point screening method was selected to obtain PS points in the study area. The interferometric phase of a pixel located at coordinates $(x, r)$ in interferogram $j$ can be expressed as follows:

$$
\begin{gathered}
\delta \phi_{j}(x, r)=\delta \phi_{\text {def }, j}(x, r)+\delta \phi_{a t m, j}(x, r)+ \\
\delta \phi_{\text {topo }, j}(x, r)+\delta \phi_{o r b, j}(x, r)+ \\
\delta \phi_{\text {noise }, j}(x, r)
\end{gathered}
$$

where $\delta \phi_{d e f, j}(x, r)$ denotes the deformation phase, $\delta \phi_{a t m, j}(x, r)$ refers to the atmospheric phase error. $\delta \phi_{o r b, j}(x, r)$ is the orbit phase error. $\delta \phi_{\text {topo }, j}(x, r)$ represents the terrain phase error caused by inaccurate external $\mathrm{DEM}$, and $\delta \phi_{\text {noise, } j}(x, r)$ is the random noise phase. 


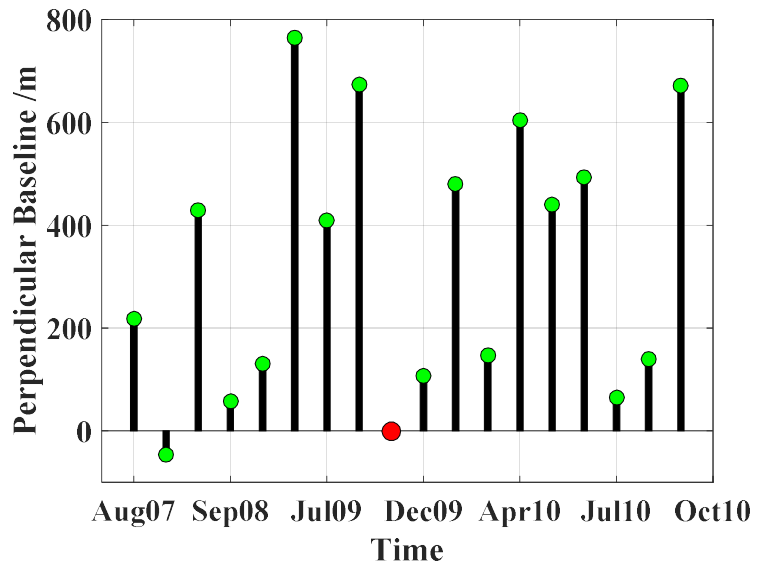

Figure 3. Interferograms processed by PSInSAR technique. The red dot denotes the master image. The black bars represent the pairs from which the interferograms were generated. The green dot denotes the slave image.

The components of atmosphere phase error, terrain phase error, orbit phase error, and noise phase were estimated accurately. After removing the above-mentioned components from the interferometric phase of the PS point, the deformation phase of the PS point can be obtained. and then the deformation rate and deformation time series of the PS point can be calculated.

\section{EXPERIMENTAL RESULTS AND ANALYSIS}

\subsection{Surface subsidence rate results and analysis}

Figure 3 shows the average subsidence rate map in Langfang area from 2007 to 2010 derived by PSInSAR technique. Negative values in Figure 3 denote surface subsidence, whereas positive values represent surface uplift. As shown in Figure 3, the high-coherence target points acquired by PSInSAR are more dense in urban areas than that in suburban areas. During the study period, the annual average subsidence rate in Langfang area ranged from $-77 \mathrm{~mm} /$ year to $4 \mathrm{~mm} /$ year, and the largest subsidence rate was detected in Nanjianta (NJT) Town, Guangyang District (GY).

As illustrated in Figure 3, uneven subsidence is obvious in the study area, and the main subsidence areas are mainly located in urban area, while the surface subsidence in the suburb is small and relatively stable. The major subsidence areas in Langfang are mainly distributed in Anci (AC) and Guangyang (GY) Disticts, but the subsidence in GY is more serious. Four significant subsidence areas in GY were identified, namely NJT, Jiuzhou (JZ) Town, Wanzhuang (WZ) Town and Economic and Technological Development Zone (ETDZ) subsidence areas. The surface subsidence in the north and east of Langfang is relatively stable, and most subsidence rates in these areas range from $-15 \mathrm{~mm} /$ year to $4 \mathrm{~mm} /$ year. These areas are basically suburban areas, and the surface geological structure is less affected by human activities. Compared and analyzed the four subsidence areas distributed in GY, the subsidence rates in WZ and $\mathrm{JZ}$ subsidence areas are lower, and the subsidence funnels in ETDZ and NJT subsidence areas are larger and more serious. Maximum subsidence rates in ETDZ and NJT reach -45 $\mathrm{mm} /$ year and $-77 \mathrm{~mm} /$ year, respectively. It can be seen from the spatial distribution of surface subsidence in Figure 3 that the surface subsidence in Langfang has a tendency to gradually expand around NJT as the center, and the extent and trend of the expansion to the north and west of Langfang are more serious.

During the study period, the most serious subsidence was detected in Nanjianta Town, Guangyang District, where residents live intensively. The water consumption of urban development and residents in this area is large. Besides, the water supply in Langfang mainly came from groundwater extraction. In addition, this area is mainly quaternary sediments with high compressibility. Due to the excessive exploitation of groundwater, the groundwater level gradually declined, resulting in the obvious uneven surface subsidence in NJT area and forming an obvious subsidence funnel.

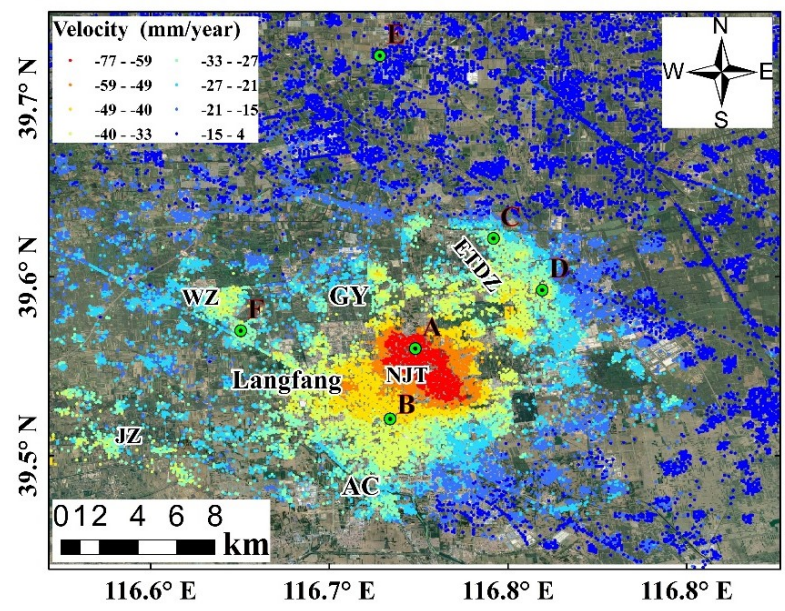

Figure 4. Average subsidence rate in the study area during the period from 2007 to 2010

To assess precision of subsidence rates extracted from ENVISAT ASAR data by PSInSAR technique, standard deviations of subsidence rates were statistically analyzed. Figure 5 shows the probability density function of the standard deviation of subsidence rate from all monitoring target points in the study area. The standard deviations of the subsidence rates range from $0.8 \mathrm{~mm} /$ year to $9.3 \mathrm{~mm} /$ year, and $70.4 \%$ of monitoring target points are less than $3 \mathrm{~mm} /$ year. Additionally, the standard deviation of the subsidence results derived by PSInSAR is $2.7 \mathrm{~mm} /$ year. According to the above-mentioned analysis, surface subsidence derived by PSInSAR technique using ASAR images features relatively high reliability and precision.

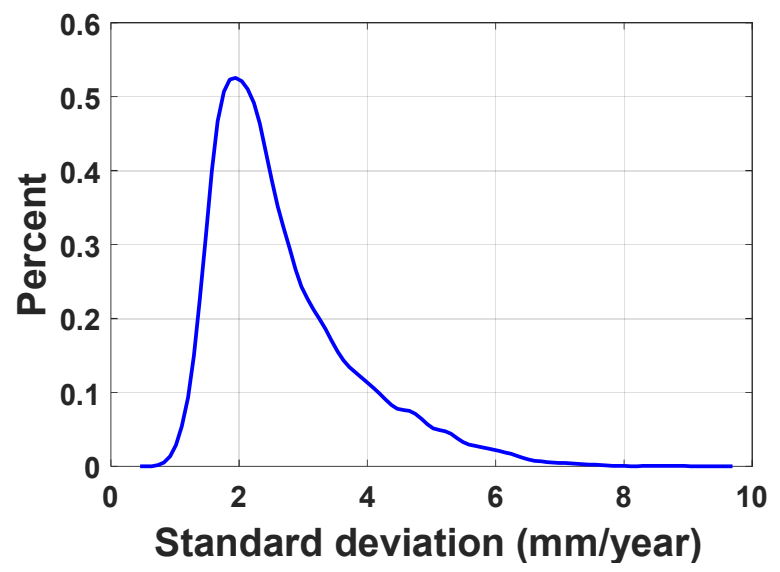

Figure 5. Probability density function of standard deviation of average subsidence rates 


\subsection{Surface subsidence time series result and analysis}

To analyze the surface subsidence evolution with respect to time in Langfang area, we selected 6 PS points (i.e., A, B, C, D, $\mathrm{E}$ and $\mathrm{F}$ illustrated in Figure 4) distributed in different subsidence areas, and compared and analyzed the subsidence time series of these 6 PS points during the study period. The results are shown in Figure 6-11.

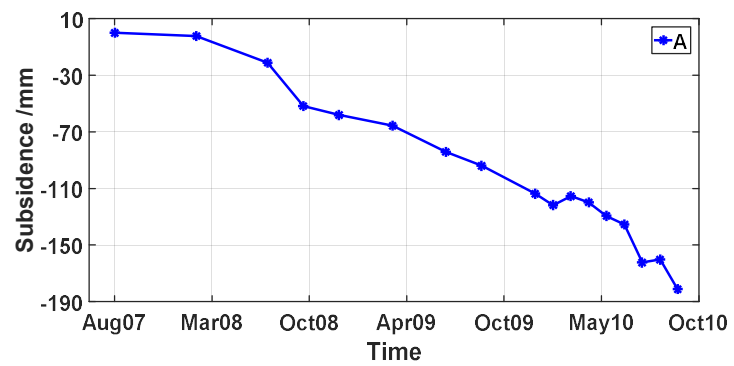

Figure 6. Surface subsidence time series with respect to PS point labeled as A in Figure 4

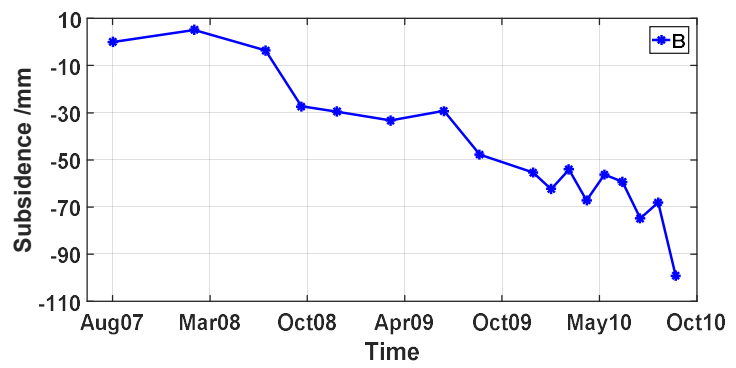

Figure 7. Surface subsidence time series with respect to PS point labeled as B in Figure 4

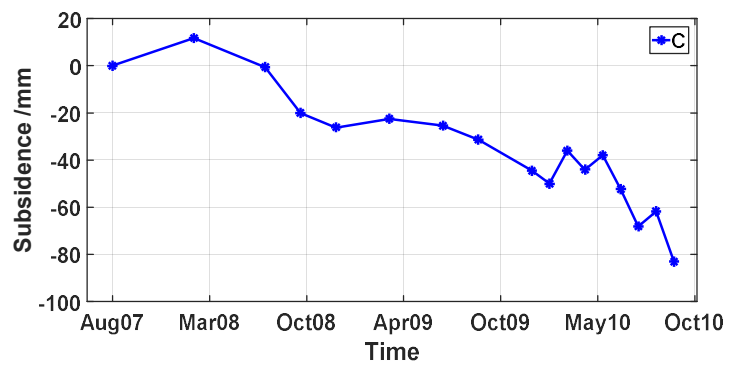

Figure 8. Surface subsidence time series with respect to PS point labeled as $\mathrm{C}$ in Figure 4

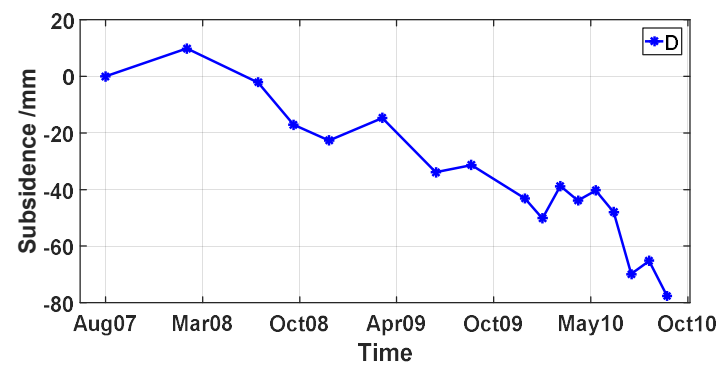

Figure 9. Surface subsidence time series with respect to PS point labeled as D in Figure 4

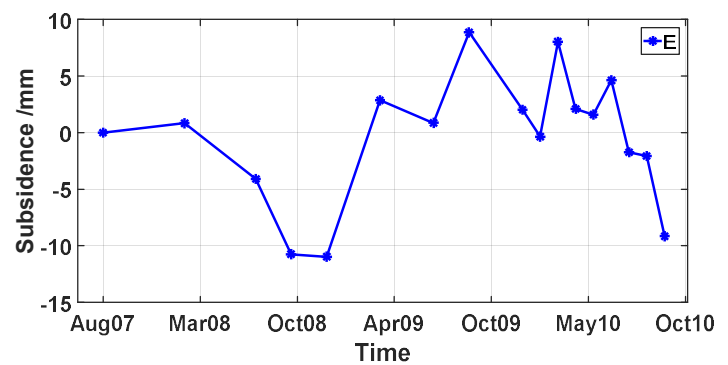

Figure 10. Surface subsidence time series with respect to PS point labeled as E in Figure 4

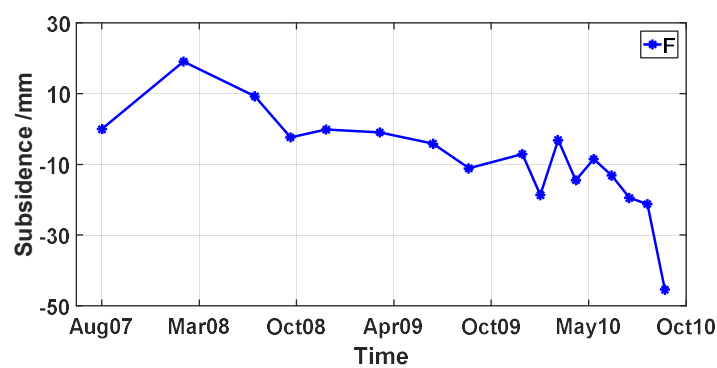

Figure 11. Surface subsidence time series with respect to PS point labeled as $\mathrm{F}$ in Figure 4

As shown in Figure 6-11, subsidence time series of these 6 PS points acquired by PSInSAR show nonlinear subsidence. As the 6 PS points are distributed in different spatial location, their accumulated subsidence is also different. Among the selected points, $\mathrm{A}$ is located in the most serious subsidence area, the NJT area (Figure 4). The subsidence of A continues to increase, and the accumulated subsidence during the study period has reached $-181 \mathrm{~mm}$. Figure 7 shows the subsidence time series of $\mathrm{B}$ located in $\mathrm{AC}$ area. The nonlinear change is obvious at $\mathrm{B}$, and the maximum subsidence is $-99 \mathrm{~mm}$. Figures 8 and 9 respectively show the subsidence time series change at $\mathrm{C}$ and $\mathrm{D}$ located in ETDZ. The accumulative subsidence at C and D reach $-83 \mathrm{~mm}$ and $-78 \mathrm{~mm}$, respectively. $\mathrm{E}$ is located in the suburb of Langfang, which is less affected by groundwater exploitation and construction. The subsidence of $\mathrm{E}$ is basically less than $10 \mathrm{~mm}$. F is located in the WZ subsidence area, and the accumulated subsidence of this point is $-45 \mathrm{~mm}$. Overall, the surface subsidence in Langfang area shows nonlinear subsidence, and the severity of surface subsidence is greatly affected by groundwater overexploitation.

\section{CONCLUSIONS}

In this study, based on the ASAR images, we used PSInSAR technique to obtain the surface subsidence information in Langfang area from August 1, 2007 to September 29, 2010, and investigated surface subsidence spatial-temporal characteristics in Langfang. The experimental results show that uneven surface settlement in Langfang is obvious, and four significant subsidence areas (i.e., NJT, JZ, WZ and ETDZ subsidence areas) were identified in Langfang. Among the above-mentioned subsidence areas, NJT subsidence area is the most serious subsidence area with the maximum subsidence rate reaching $-77 \mathrm{~mm} /$ year. A statistical analysis of the standard 
deviations of the average subsidence rates indicated that $70.4 \%$ of the monitoring target point standard deviations in the study area are less than $3 \mathrm{~mm} / \mathrm{year}$, and the standard deviation of the PSInSAR-derived subsidence result in the study area is 2.7 $\mathrm{mm} /$ year, demonstrating that the PSInSAR technique is effective for surface subsidence monitoring and analyzing in Langfang.

\section{ACKNOWLEDGEMENTS}

This work was supported by the Guangxi Science and Technology Plan Project (Grant No. GUIKE AD19110107); the Key Laboratory of Geospace Environment and Geodesy, Ministry of Education, Wuhan University (Grant No. 18-01-01) the Natural Science Foundation of Guangxi (Grant No. 2018GXNSFBA050006); the Wuhan Science and Technology Plan Project (Grant No. 2019010702011314); the National Natural Science Foundation of China (Grant No. 41604019); and the Foundation of Guilin University of Technology (Grant No. GUTQDJJ2018036). The authors wish to thank the ESA for arranging the Sentinel-1A data, NASA for providing the SRTM3 DEM data, ESA for releasing the POD data.

\section{REFERENCES}

Zhou L, Guo J, Hu J, et al., 2017. Wuhan Surface Subsidence Analysis in 2015-2016 Based on Sentinel-1A Data by SBASInSAR. Remote Sens, 9(10):982-1003.

Li Z, Elliott J R, Feng W, et al., 2011. The 2010 MW 6.8 Yushu (Qinghai, China) earthquake: Constraints provided by InSAR and body wave seismology. J. Geophys. Res-Sol. Ea., 116(B10):381-386.

Calò F, Ardizzone F, Castaldo R, et al., 2014 Enhanced landslide investigations through advanced DInSAR techniques: The Ivancich case study, Assisi, Italy. Remote Sens. Environ., 142(3):69-82.

Guo J, Zhou L, Yao C, et al., 2016. Surface Subsidence Analysis by Multi-Temporal InSAR and GRACE: A Case Study in Beijing. Sensors, 16(9):1495-1513.

Ferretti A, Prati C, Rocca F.,2001. Permanent scatterers in SAR interferometry. IEEE Trans. Geosci. Remote Sens., 39(1):8-20.

Beradino P, Fornaro G, Lanari R, Sansosti E., 2002. A New Algorithm for Surface Deformation Monitoring Based on Small Baseline Differential SAR Interferograms. IEEE Trans. Geosci. Remote Sens., 40(11):2375-2383.

Song Y, Liu G, Zhang R., 2016. Monitoring significant ground subsidence by using new small baseline subset multiple temporal InSAR approach. Remote Sens. Inform., 31(1): 84-88.

Bai L, Jiang L, Wang H, et al., 2016. Spatiotemporal Characterization of Land Subsidence and Uplift (2009-2010) over Wuhan in Central China Revealed by TerraSAR-X InSAR Analysis. Remote Sens., 8(4):350.

Ferretti A, Prati C, Rocca F., 2000. Nonlinear subsidence rate estimation using permanent scatterers in differential SAR interferometry. IEEE Trans. Geosci. Remote Sens., 38(5):22022212.
Hooper A, Zebker H, Segall P, et al., 2004. A new method for measuring deformation on volcanoes and other natural terrains using InSAR persistent scatterers. Geophys. Res. Lett., $31(23): 1-5$.

Hooper A, Segall P, Zebker H., 2007. Persistent scatterer interferometric synthetic aperture radar for crustal deformation analysis, with application to Volcán Alcedo, Galápagos. $J$. Geophys. Res-Sol. Ea., 112(B7): 407-428.

Perissin D, Prati C, Engdahl M E, et al., 2006. Validating the SAR Wavenumber Shift Principle with the ERS-Envisat PS Coherent Combination. IEEE Trans. Geosci. Remote Sens., 44(9):2343-2351 